\title{
PREVALENCE OF HYPERTENSION IN 500 TEACHERS OF PESHAWAR UNIVERSITY AND ITS ASSOCIATED CAUSATIVE FACTORS
}

\author{
Riaz Gul' ${ }^{1}$, Hira Gul' ${ }^{1}$, Sofia Shehzad ${ }^{2}$, Adil Zarif ${ }^{1}$ \\ 1. Northwest School of Medicine \\ 2. Sardar Begum Dental College
}

ABSTRACT:

\section{OBJECTIVE:}

The main objective of this study was to determine the prevalence of hypertension in 500 teachers of Peshawar University and to study its associated causative factors.

\section{METHODOLOGY:}

A cross sectional study was conducted over 500 teachers from different departments of university of Peshawar from $15^{\text {th }}$ September 2017 to $15^{\text {th }}$ December 2017. Random sampling technique was used to collect the required sample size. All teachers who were involved in active teaching were included in sample while teachers with other major illness like diabetes or congenital heart defects were excluded from the study. A semi structured questionnaire was used as study tool for data collection. The information was collected and presented in the form of graphs and charts. Statistical analysis was done using SPSS version 17.

\section{RESULTS:}

500 teachers from various departments of Peshawar University were interviewed. Out of them 353 (70.6\%) were male and 147 (29.4\%) were female. Out of the total sample population 128 had hypertension giving a prevalence of $25.6 \%$. Prevalence was high among teachers above 40 years of age (110 of 128) and those have a positive family history of hypertension (33\% of hypertensive). $38.3 \%$ of the total overweight and $55.6 \%$ of total obese were found to be hypertensive. $29.3 \%$ of smokers were hypertensive as compared to $25.4 \%$ of non-smokers. All the hypertensive patients seemed to be stressed in one way or the other.

\section{CONCLUSION:}

The studies showed that the prevalence was high among teachers above 40 years of age, smokers and those having a stressful routine.

KEYWORDS: Hypertension, Prevalence, Sedentary Lifestyle

\section{INTRODUCTION:}

Hypertension is a chronic medical condition that affects people around the world. The factors influencing blood pressure are diet, exercise,

\begin{tabular}{c} 
Correspondence \\
Riaz Gul \\
Department Community Medicine \\
Northwest School of Medicine \\
Email: riazgul_70@yahoo.com \\
Phone: 0345-9386866 \\
\hline
\end{tabular}
smoking and lifestyle. People from all walks of life may be hypertensive, as they might be exposed to the causative factors of hypertension. It is therefore of immense importance to find out the prevalence of hypertension among them. High blood pressure, termed hypertension is a condition that afflicts almost 970 million people worldwide and is leading cause of morbidity and mortality ${ }^{1}$. More than $14 \%$ of general population is hypertensice $^{2}$ and $50 \%$ of them are not even aware that they are hypertensive ${ }^{3}$. This disease is 
sometimes called the "silent killer". It is usually asymptomatic until the damaging effects are observed. The causative factors for hypertension usually include unhealthy lifestyle, obesity and advanced age. These factors could be easily changed by modifying their lifestyles and behavior of the individual. Early detection and prompt treatment can reduce the deaths ${ }^{3}$. Arteries are vessels that carry blood from the pumping heart to all the tissues and organs of the body. Emotional tension and stress can temporarily increase blood pressure. Normal blood pressure is below 120/80; blood pressure between $120 / 80$ and $139 / 89$ is called "pre-hypertension" and a blood pressure of $140 / 90$ or above is considered high ${ }^{3}$. An elevation of the systolic and or diastolic blood pressure increases the risk of developing heart (cardiac) disease, kidney (renal disease), hardening of the arteries (atherosclerosis or arteriosclerosis), eye damage, and stroke (brain damage). These complications of hypertension are often referred to chronic high blood pressure. The diagnosis of high blood pressure is important ${ }^{4}$. According to the latest report of the Joint National Committee (JNC VII) on detection, evaluation and treatment of high blood pressure, a blood pressure measurement of less than $130 / 85 \mathrm{mmHg}$ is considered "normal" while 130-140/85-90 mmHg is defined as "high normal". The upper normal level of blood pressure 140/90 $\mathrm{mmHg}$ and above this value, the blood pressure constitutes hypertension ${ }^{5}$. Hypertension puts the heart and arteries under greater strain than normal. The heart becomes enlarge and the arteries can become scarred and less elastic, increasing the risk of heart attack or stroke. Its treatment is life long to avoid complications. The higher the blood pressure, the sooner the complications caused by high blood pressure include smoking, diabetes and high cholesterol 6 . The rise in diastolic blood pressure was an important risk factor than systolic elevations previously, but it is now known that in older people systolic hypertension represents a greater risk according to the American Heart Association $^{3}$. High blood pressure affects approximately one in three adults in the United Stated which accounts for 73 million people. Hypertension is clearly a major public health problem ${ }^{7}$. The main factors that predispose a person to hypertension are advanced age, sedentary lifestyle, lack of exercise, smoking, increased salt intake, stressful routine, diet rich in fats, obesity and family history of hypertension ${ }^{8}$. Employees all over the world are exposed to stress because of work burden, which leads to obesity. These factors along with family history, smoking and unhealthy diet leads to the development of hypertension ${ }^{9}$. The main purpose of this study is to determine the prevalence of hypertension in teachers working in different departments of Peshawar University and to identify the major risk factors involved in its causation.

\section{METHODOLOGY:}

The setting for this study is the University of Peshawar campus. Study was carried out in the following educational institutions; Khyber Medical College, University of Engineering, Agriculture University, Institute of Management Sciences and Islamic University. Our study population were the teachers of Peshawar University campus. The total size of study population is about 2000 teachers. The sample size was 500 teachers. Sampling technique used was simple random sampling. Each member of the population will have an equal chance of being selected. The study design used was cross sectional descriptive study design, which is retrospective in nature. A semi structured questionnaire was distributed among the teachers having both open ended and close ended questions. Blood pressure was measured with aneroid sphygmomanometers after the participant had been seated and rested for 5 minutes. Two measurements were taken at an interval of 2 minutes between readings, and the average of the 2 recordings was accepted as the subject's blood pressure. All teachers who were employed for more than 3 years were included in the current study while those with experience less than 3 years were excluded.

\section{RESULTS:}

500 subjects were questioned and tested for the purpose of this study. Out of $500,11 \%$ (55) were 
below the age of 30 years, $21.8 \%$ (109) were in the age group of $31-40$ years, $36.6 \%$ (183) of the subjects were of $41-50$ years of age, $27.8 \%$ (139) of the teachers were in the age group of 51-60 years, while $2.8 \%$ (14) were above the age of 60 . $70.6 \%$ (353) of the teachers were males while $29.4 \%(147)$ of the teachers were females. Out of $500,21.6 \%$ (108) were demonstrators, $32.2 \%$ (161) were lecturers, $18.4 \%$ (92) were assistant professors, $15.8 \% \quad(79)$ were associate professors, $7.6 \%$ (38) were professors while $4.4 \%$ (22) had post not mentioned in the questionnaire (interns). $72.2 \%$ (361) of the teachers interviewed were married, 23\% (115) were unmarried. After checking the blood pressure, we found out that $25.6 \%(128)$ of the teachers were hypertensive while $74.4 \% \quad(372)$ of the teachers were normotensives. None of the teachers were found to be hypotensive. By calculating the Body Mass Index (BMI) we found out that $6.4 \%$ (32) of the teachers were underweight, $66.8 \%$ (334) were normal weight and $21.4 \%$ (107) were found to be overweight while $5.4 \%$ (27) were found to be obese. Out of the 353 male teachers, $27.5 \%$ (87 of 353 ) were found to be hypertensive whereas $72.5 \%$ (266 of 353 ) of male teachers were found to have normal blood pressure. Out of the 147 female teachers, $27.9 \%$ (41 of 147) were found to be hypertensive, $72.1 \%$ (106 of 147) of the female teachers had normal blood pressure. Hypertension distribution by age group for teachers under age 30 (total $=55,11 \%$ of 500 ), $10.9 \%$ ( 6 of 55 ) were found to be hypertensive. In teachers between age range 31-40 (total $=109$, $21.8 \%$ of 500 ), $11 \%$ (12 of 109 ) were found to be hypertensive. In age group 41-50 (total= 182, $36.6 \%$ of 500 ), $28.5 \%$ (52 of 183) were hypertensive. In age group 51-60 (total= 139, $27.8 \%$ of 500 ), $31.7 \%$ (49 of 139) were hypertensive. In teacher above age 60 (total $=14$, $2.8 \%$ of 500 ), $64.3 \%$ (9 of 14 ) were hypertensive. As for the familial hypertension, out of the 103 teachers who had at least one direct relative suffering from hypertension $42.7 \%$ (44 of 103) were hypertensives. Out of 397 teachers who did not have any family member suffering from hypertension, $21.4 \%$ ( 85 of 397 ) were found to be hypertensive. As for the relationship between obesity and hypertension, out of the $6.4 \%$ teachers who were underweight, $6.3 \%$ (2 of 32 ) were hypertensive, while others were normal (30). Out of the $66.8 \%$ teachers who had a normal BMI, $21 \%$ (70 of 334) were found to be hypertensive, and 264 were normal. $21.4 \%$ of the total teachers were overweight, $38.3 \%$ (41 of 107) of these were hypertensive, while the rest were normal (66). $5.4 \%$ of the teachers were obese, $55.6 \%$ (15 of 27 ) of these were hypertensive, and the rest were normal (12). Relationship of smoking with hypertension reveals that $26.6 \%$ of the teachers were smokers, $29.3 \%$ (39 of 133) of these were hypertensive, and the rest were normal (94). $73.4 \%$ of the teachers were nonsmokers, $24.3 \%$ (89 of 133) of these were hypertensive, rest were found to be normal (278). The relationship between stress and hypertension indicates that $83.6 \%$ (481 of 500 ) of the teachers said they suffered from stress, $26.8 \%$ (112 of 418 ) of these were found to be hypertensive, while the rest were normal (66). $16.4 \%$ of the 500 teachers said they do not feel unusual mental stress, $19.5 \%$ (16 of 82 ) out of these were found to be hypertensive, while the remaining were normal (66). Relationship between lifestyle and hypertension shows that $28.6 \%$ (143 of 500 ) of the teachers said they led an active life. Out of these $15.4 \%$ (22 of 143 ) were hypertensive. $63.8 \%$ (319 of 500) of the teachers said they had an average lifestyle. Out of these $28.6 \%$ (91 of 319) were found to be hypertensive. $7.6 \%$ (38 of 500 ) of the teachers said they led a predominantly sedentary life. Out of these $39.5 \%$ ( 15 of 38 ) were found to be hypertensive. 
Table 1: Health Status of Respondents

\begin{tabular}{|c|c|c|c|}
\hline Characteristics & Category & Frequency & Percentage \\
\hline \multirow{4}{*}{ BP Status } & Normotensive & 372 & 74.4 \\
\cline { 2 - 4 } & Hypertensive & 128 & 25.6 \\
\cline { 2 - 4 } & Total & 500 & 100 \\
\hline \multirow{4}{*}{ Lifestyle } & Active & 143 & 28.6 \\
\cline { 2 - 4 } & Average & 319 & 63.8 \\
\cline { 2 - 4 } & Sedentary & 38 & 7.6 \\
\cline { 2 - 4 } & Total & 500 & 100 \\
\hline \multirow{3}{*}{ Regular Exercise } & Yes & 94 & 18.8 \\
\cline { 2 - 4 } & No & 406 & 81.2 \\
\cline { 2 - 4 } & Total & 500 & 100 \\
\hline \multirow{3}{*}{ High Stress } & Yes & 418 & 83.6 \\
\cline { 2 - 4 } & No & 82 & 16.4 \\
\cline { 2 - 4 } & Total & 500 & 100 \\
\hline
\end{tabular}

Table 2: Relationship Between Gender and Hypertension

\begin{tabular}{|c|c|c|c|c|}
\hline \multirow{2}{*}{ Gender } & Normal & Hypertensive & Total \\
\hline \multirow{2}{*}{ Male } & Count & 266 & 87 & \multirow{3}{*}{353} \\
\cline { 2 - 4 } & \%within Gender & $72.5 \%$ & $27.5 \%$ & \\
\hline \multirow{2}{*}{ Female } & Count & 106 & 41 & \multirow{2}{*}{147} \\
\cline { 2 - 5 } & \%within Gender & $72.1 \%$ & $27.9 \%$ & 500 \\
\hline
\end{tabular}

Table 3: Relationship Between Age and Hypertension

\begin{tabular}{|c|c|c|c|c|}
\hline \multicolumn{2}{|c|}{ Age Group } & Normal & Hypertensive & Total \\
\hline \multirow{2}{*}{$<30$} & Count & 49 & 6 & \multirow{2}{*}{55} \\
\hline & \%in Age Group & $89 \%$ & $11 \%$ & \\
\hline \multirow{2}{*}{$31-40$} & Count & 97 & 12 & \multirow{2}{*}{109} \\
\hline & \%in Age Group & $89 \%$ & $11 \%$ & \\
\hline \multirow{2}{*}{$41-50$} & Count & 131 & 52 & \multirow{2}{*}{183} \\
\hline & \%in Age Group & $71.5 \%$ & $28.5 \%$ & \\
\hline \multirow{2}{*}{$51-60$} & Count & 90 & 49 & \multirow{2}{*}{139} \\
\hline & \%in Age Group & $64.7 \%$ & $25.3 \%$ & \\
\hline \multirow{2}{*}{$>60$} & Count & 5 & 9 & \multirow{2}{*}{14} \\
\hline & \%in Age Group & $35.7 \%$ & $64.5 \%$ & \\
\hline \multicolumn{2}{|c|}{ Total } & 372 & 128 & 500 \\
\hline
\end{tabular}


Table 4: Relationship Between Body Mass Index and Hypertension

\begin{tabular}{|c|c|c|c|c|}
\hline \multicolumn{2}{|c|}{ Age Group } & Normal & Hypertensive & Total \\
\hline \multirow{2}{*}{ Underweight GHT } & Count & 30 & 2 & 32 \\
\cline { 2 - 5 } & \%in Category & $94 \%$ & $6 \%$ & \multirow{2}{*}{334} \\
\hline \multirow{2}{*}{ Normal } & Count & 264 & 70 & \multirow{2}{*}{107} \\
\cline { 2 - 5 } & \%in Category & $79 \%$ & $21 \%$ & 27 \\
\hline \multirow{2}{*}{ Overweight } & Count & 66 & $38.3 \%$ & 27 \\
\cline { 2 - 5 } & \%in Category & $61.7 \%$ & 15 & 500 \\
\hline
\end{tabular}

Table 5: Relationship Between High Stress and Hypertension

\begin{tabular}{|c|c|c|c|c|}
\hline \multicolumn{2}{|c|}{ High Stress } & Normal & Hypertensive & Total \\
\hline \multirow{2}{*}{ Yes } & Count & 306 & 112 & \multirow{2}{*}{418} \\
\cline { 2 - 5 } & \%in Category & $73.2 \%$ & $26.8 \%$ & \multirow{2}{*}{82} \\
\multirow{2}{*}{ No } & Count & 66 & 16 & 500 \\
\cline { 2 - 5 } & \%in Category & $80.5 \%$ & $19.5 \%$ & 128 \\
\hline \multicolumn{2}{|c|}{ Total } & 372 & & 500 \\
\hline
\end{tabular}

Table 6: Relationship Between Sedentary Lifestyle and Hypertension

\begin{tabular}{|c|c|c|c|c|}
\hline \multicolumn{2}{|c|}{ Lifestyle } & Normal & Hypertensive & Total \\
\hline \multirow{3}{*}{ Active } & Count & 121 & 22 & \multirow{2}{*}{143} \\
\cline { 2 - 5 } & \%in Category & $84.6 \%$ & $15.4 \%$ & \multirow{2}{*}{319} \\
\hline \multirow{3}{*}{ Average } & Count & 228 & 91 & \multirow{2}{*}{38} \\
\cline { 2 - 5 } & \%in Category & $71.4 \%$ & $28.6 \%$ & \\
\hline \multirow{2}{*}{ Sedentary } & Count & 23 & $3.5 \%$ & 500 \\
\cline { 2 - 5 } & \%in Category & $60.5 \%$ & 128 & \multirow{2}{*}{5} \\
\hline
\end{tabular}




\section{DISCUSSION:}

According to our study the prevalence of hypertension in teachers of Peshawar University is $25.6 \%$ (128 of 500$)$. This value is slightly higher than the worldwide prevalence but as compared to the prevalence within the country $(33 \%)$ it is less than the general population ${ }^{10}$. Many factors may be involved in this but mainly as mentioned above teachers being well educated are more aware of general health problems and take preventive measures but at the same time they lead a predominantly sedentary lifestyle and have a high stress job. Gender wise prevalence did not reveal any difference in the prevalence of the diseases. Out of 353 males $27.5 \%$ were hypertensive while out of 147 females $27.9 \%$ were hypertensive. Both figures were almost identical thus we may deduce than gender does not affect the prevalence of this disease too much ${ }^{9}$. Teachers in age group less than 30 years had a prevalence of $10.9 \%$. In the age group 31-40, prevalence of hypertension was $11 \%$. Among 41 50 years old prevalence was $28.5 \%$ and in $51-60$ years age group this prevalence rose to $31.7 \%$. Above 60 years the prevalence was $64.8 \%$. This shows a direct relation between old age and hypertension prevalence ${ }^{11}$. Familial trend was also observed in the results. Among those with a family history of hypertension (103 out of 500) the prevalence was $42.7 \%$ as opposed to $21.4 \%$ prevalence in those with no family history of hypertension. Obesity also showed relation with hypertension of the 107 overweight subjects' prevalence of hypertension that was $38.3 \%$ as compared to $21 \%$ among the normal BMI subjects. In obese subjects the prevalence was $55.6 \%$. This shows that obesity has a very large role in development of hypertension. Smoking was another factor which we tried to study in relation to hypertension. Among the smokers (133) prevalence of hypertension was $20.3 \%$ while among non-smokers' prevalence dropped to $24.3 \%$. This shows a not so marked but still significant difference. Mental stress and tension also act as a contributing factor for development of hypertension. According to our study results prevalence of hypertension in teachers who said they had highly stressful life been $26.8 \%$ as opposed to $19.5 \%$ among those who led a stressfree life. This is more so important because in habits section of questionnaire when asked about stress, 418 out of 500 (84.6\%) subjects answered that they did indeed suffer from high mental stress. This is an important factor and should be looked at it in the future ${ }^{12}$. Having a sedentary or inactive lifestyle also contributes to hypertension. Among that leading active life prevalence was $15.4 \%$, and leading normal average lifestyle prevalence was $28.6 \%$, while those leading a sedentary life were having a prevalence of $39.5 \%$ which shows a significant role of sedentary lifestyle in development of hypertension. The questionnaire was mainly designed to determine the awareness level of the population towards this particular problem. Being well educated class the teacher's awareness about the problem was satisfactory, but more efforts should be done to further improve the situation. Awareness about the basic problem was sufficient but was lesser about the prevention and treatment of this problem. Regular medical checkup should be encouraged because only $31.6 \%$ of the subjects answered that they got BP checked regularly.

\section{CONCLUSION:}

Multiple factors are responsible for the prevalence of hypertension. The studies showed that the prevalence was high among teachers above 40 years of age, smokers and those having a stressful routine. 


\section{REFERENCES:}

1. Srinivasan SR, Myers L, Berenson GS. Changes in metabolic syndrome variables since childhood in prehypertensive and hypertensive subjects: the Bogalusa Heart Study. Hypertension. 2006;48(1):33-9.

2. Cutler JA, Sorlie PD, Wolz M, Thom T, Fields LE, Roccella EJ. Trends in hypertension prevalence, awareness, treatment, and control rates in United States adults between 1988-1994 and 1999-2004. Hypertension. 2008;52(5):818-27.

3. Javed A, Aziz S, Raza A. Prevalence of cad in females with hypertension and diabetes millitus presenting with chest. Pak Heart J. 2006;39(1-2):9-12.

4. Scheer FA, Van Montfrans GA, van Someren EJ, Mairuhu G, Buijs RM. Daily nighttime melatonin reduces blood pressure in male patients with essential hypertension. Hypertension. 2004;43(2):192-7.

5. Berkow SE, Barnard ND. Blood pressure regulation and vegetarian diets. Nutr Rev. 2005;63(1):1-8.

6. Bener A, Al-Suwaidi J, Al-Jaber K, Al-Marri S, Dagash $\mathrm{MH}$, Elbagi IE. The prevalence of hypertension and its associated risk factors in a newly developed country. Saudi Med J. 2004;25(7):918-22.

7. Kaplan NM, Lieberman E. Clinical hypertension. $3^{\text {rd }}$ ed. Baltimore: Williams \& Wilkins; 1982.

8. Nicholas AB, Nicki RC, Brian RW. Diseases of cardiovascular system: Davidson's principles and practice of medicine. $18^{\text {th }} \mathrm{ed}$. England: Churchill Livingstone; 1999.

9. Kumar V, Abbas AK, Fausto N, Mitchell RN. Robbins basic pathology. $8^{\text {th }}$ ed. Philadelphia: Saunders/Elsevier; 2007.

10. Mohamed, Ansari MA, Malik, Qadir G, Mubasher, Mahmuda et al. Community medicine and public health. $4^{\text {th }}$ ed. Karachi: Time Traders; 1998.
11. Kumar P, Clark ML. Clinical medicine. $3^{\text {rd }}$ ed. Bailliere Tindall; 1998.

12. Hart JT. Hypertension. Library of the General Practitioner Series. Churchill Livingstone; 1980. 